\title{
Modelling of quality technical education using path analysis
}

\author{
N. N. $\operatorname{Wan}^{1} \quad$ N. R. M. Suradi ${ }^{2} \quad$ Z. Mustafa ${ }^{3}$ \\ W. R. Ismail ${ }^{4} \quad$ Z. M. Ali ${ }^{5} \quad$ F. A. A. Shahabuddin 6
}

(Received 1 February 2010; revised 3 March 2011)

\begin{abstract}
This study discusses the relationship between education service quality factors, customer value and customer satisfaction in measuring the quality of technical education in a technical university in Malaysia. To examine these relationships, a model from past study on engineering education quality measures technical education quality. This model is also expanded to a path model which combines all relationships existing in the model. Path analysis simultaneously tests all relationships between education service quality factors, customer value and customer satisfaction. As a result, a suitable model describing the quality of technical education is established. This study finds there is a direct effect between some education service quality factors, namely customer focus, course delivery, campus facilities and communication, and customer satisfaction. There is also an indirect relationship between education service quality factors (specifically commitment of top management
\end{abstract}

http://anziamj . austms.org.au/ojs/index.php/ANZIAMJ/article/view/2541 gives this article, (c) Austral. Mathematical Soc. 2011. Published March 24, 2011. ISSN 1446-8735. (Print two pages per sheet of paper.) Copies of this article must not be made otherwise available on the internet; instead link directly to this URL for this article. 
and leadership, congenial learning environment, continuous assessment and improvement) and customer satisfaction through customer value.

\section{Contents}

1 Introduction

C835

2 Methodology

C837

2.1 Commitment from top management . . . . . . . . . . C837

2.2 Customer focus . . . . . . . . . . . . . . . . . . . . . C C839

2.3 Course delivery . . . . . . . . . . . . . . . . . . . . . . C839

2.4 Communication . . . . . . . . . . . . . . . . . C839

2.5 Campus facility . . . . . . . . . . . . . . . . . C839

2.6 Congenial learning environment . . . . . . . . . . . . C840

2.7 Continual assessment and improvement processes . . . . . C C840

2.8 Customer value and customer satisfaction . . . . . . . C C840

2.9 Survey and sample . . . . . . . . . . . . . . . . C841

3 Analysis of data and results

C841

4 Discussion and conclusion

C849

References

C850

\section{Introduction}

Quality in education has been defined as excellence and value-added [1]. Quality is the degree to which the institution is successful in achieving its objectives to the satisfaction of itself, its students and the society [2]. The students are seen as the main customers in education services [3], thus their perceptions and inputs on their experiences in the higher education institution 


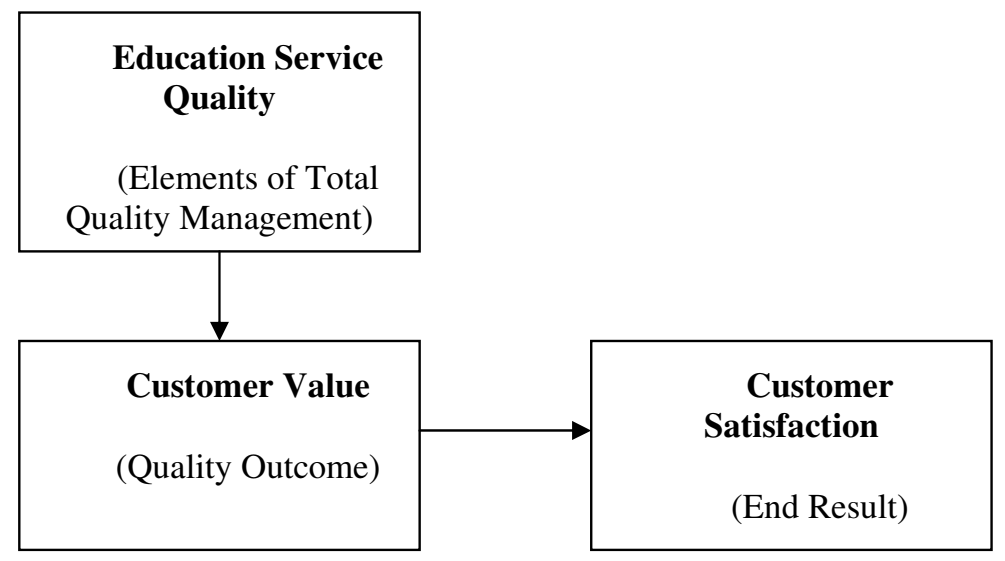

Figure 1: Conceptual framework of quality in education [8].

(HEI) should be regarded as imperative in the measuring and monitoring of quality in HEI [4]. Understanding the values from the perspectives of the customers would result in useful information in preparing necessary resources and designing academic programs that would satisfy the requirements set by the government and the prospective employers. From the industries' experiences and success stories Total Quality Management (TQM) is an effective system pursuing value addition to customers $[1,5]$.

There has been an abundance of work emphasising the importance of and the effectiveness of using TQM in measuring quality. One of the indicators used by TQM is the customer satisfaction itself [6, 7]. Kanji and Tambi [7] urged HEI to apply the principles of TQM to achieve excellence, and top management to play the important roles of identifying customers, setting the focus on establishing a long term relationship with the customers based on customer value and customer satisfaction.

Using the HEI students majoring in engineering, Sakthivel and Raju [8] developed a conceptual framework relating the Education Service Quality (ESQ), Customer Value and Customer Satisfaction as shown in Figure 1. 
In this framework, Sakhtivel and Raju provided a concept involving seven important determinants for ESQ, which were based on the TQM concept, quality outcome and final result through customer value and customer satisfaction, respectively. They found that ESQ significantly influenced Customer Value, and Customer Value significantly contributed to Customer Satisfaction. We adapted the model proposed by Sakthivel and Raju and used the model to examine the quality in technical education in a HEI in Malaysia. Furthermore, we improved the analyses of the modelling by applying path analysis. As such, the sub-models proposed by Sakhtivel and Raju, that is one that related ESQ to Customer Value and the other that related Customer Value to Customer Satisfaction were combined to provide a holistic model incorporating all three important factors for quality, and were then analysed simultaneously using path analysis (Figure 2).

\section{Methodology}

Figure 2 shows the holistic model used to study quality in technical education. There were seven important determinants for ESQ, which were obtained from the dimensions in TQM. The determinants were commitment from top management, customer focus, course delivery, communication, campus facility, congenial learning environment and assessment of and continual improvement.

\subsection{Commitment from top management}

The commitment of the top management in assuring quality in the delivery of ESQ is, inarguably, crucial. Top management must not only strive hard for an effective TQM system in education, but also manage and maintain all available resources so that an effective TQM in education environment would be realized in their institution $[1,9]$. 
Quality (sub-) model(s) by Sakthivel \& Raju [8]

\begin{tabular}{|c|}
\hline Commitment from top \\
\hline Customer focus \\
\hline Campus facility \\
\hline Communication \\
\hline Course delivery \\
\hline Learning environment \\
\hline $\begin{array}{c}\text { Continual assessment } \\
\text { and improvement }\end{array}$ \\
\hline
\end{tabular}

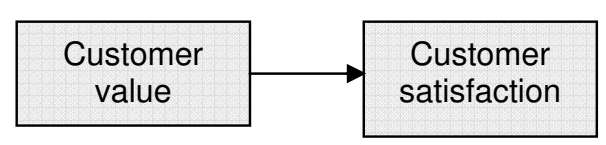

Simultaneous Quality Model using Path analysis

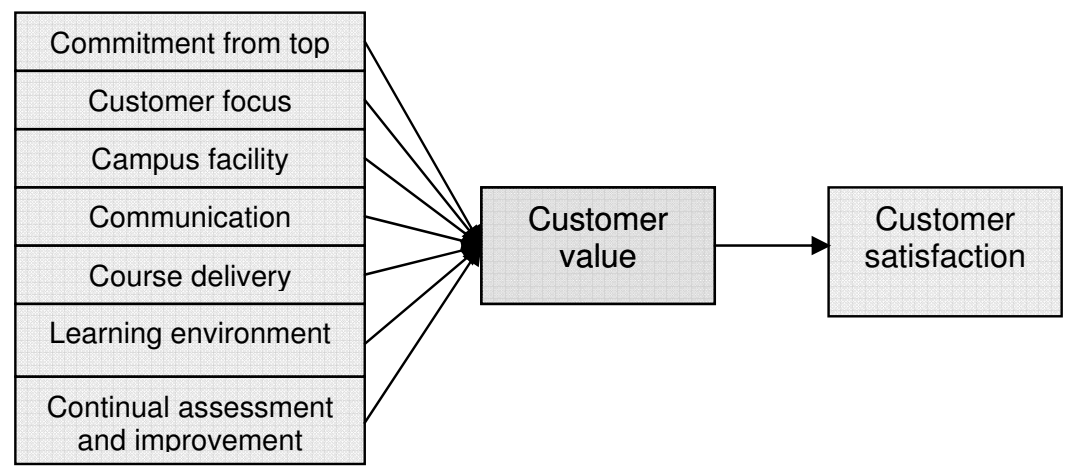

Figure 2: Adaptation of study model from Sakhtivel and Raju [8]. 


\subsection{Customer focus}

The principle of customer focus included the comprehension that customers be the reason and basis for any changes and improvement in the institution.

\subsection{Course delivery}

Course delivery referred to how the academic staff design a quality students' learning environment. The delivery mechanisms should include effective teaching techniques such as two way student-staff interaction and communication, the use of practical examples and applications of the theoretical knowledge to capture students' interest and understanding [1,9].

\subsection{Communication}

In an education environment, communication plays a crucial role in gaining knowledge. Effective communication takes place through effective teaching delivery and appropriate classroom activities. HEI should provide a variety of effective communication strategies such as e-learning, student-lecturer meeting/appointment hours, and assignment of academic advisors.

\subsection{Campus facility}

Campus facility would enhance the process of teaching and learning [9] which included well equipped lecture halls and rooms, efficient library services, well equipped and maintained computer and practical labs, transportation, 


\subsection{Congenial learning environment}

Knowledgeable and dedicated lecturers would convey their knowledge through the most user friendly, and state-of-the-art teaching and learning environment. The campus environment should also be conducive to teaching and learning. The availability and accessibility of appropriate infrastructure will help build these life-long learning experiences.

\subsection{Continual assessment and improvement processes}

Continual assessment helps identify lacking and loopholes in processes in the education system. In addition to that, assessment also helps to identify areas for improvement [9].

\subsection{Customer value and customer satisfaction}

Customer value is the quality outcome from measuring quality service. For an education service, customer value is the value for money (fees) paid by the students for the learning experiences they went through in the HEI, for the technical skills they developed.

Customer satisfaction indicated the end result of quality in service. Customer satisfaction encompasses the realisation of customer value. A system capable of producing services that fulfilled specified customer requirements and needs are said to achieve customer satisfaction. Customer satisfaction is seen as the ultimate result for all processes. Customer value strongly affects customer satisfaction. The values observed or experienced by the customers for the service they received, are significant factors in customer satisfaction. 
TABLE 1: Decompositions of Students' specialisation.

\begin{tabular}{lcc}
\hline Specialisation & Frequency & Percentage \\
\hline Diploma in Process Technology & 45 & 19.1 \\
Diploma in Environmental Technology & 49 & 20.9 \\
Diploma Food Technology & 52 & 22.1 \\
Diploma Polymer Technology & 46 & 19.6 \\
Diploma Bioprocess Technology & 26 & 11.1 \\
Degree in Bioprocess Technology & 17 & 7.2 \\
\hline Total & 235 & 100 \\
\hline
\end{tabular}

\subsection{Survey and sample}

A survey was conducted among the students of a technical education institution to obtain their perceptions on the education services they received. A set of questionnaire was designed asking multi-dimensional aspects of the ESQ, students' value and students' satisfaction. Using the summated scores of each factor, the relationships between and amongst the factors of quality in the technical education were tested.

\section{Analysis of data and results}

Altogether 235 students from six different specialisations were selected at random. Table 1 provides the distribution of the student respondents based on their specialisations.

Reliability tests were done on the data to study the internal consistency of the dimensions. The values of Cronbach alpha coefficients for seven factors of ESQ were found to be in the range of 0.761 (minimum) and 0.860 (maximum), and the alpha values were 0.866 and 0.884 for customer value and customer satisfaction, respectively. As a whole, the data was found to be reliable. Subsequently, factor analysis verified that structural relationships within each 
TABLE 2: First of two results of reliability tests and factor analysis.

\begin{tabular}{lccc}
\hline Determinant & $\begin{array}{c}\text { Cronbach } \\
\text { alpha }\end{array}$ & Item & Loading \\
\hline Education Service Quality & & \\
Commitment & 0.761 & Q1 & 0.693 \\
form top & & Q2 & 0.651 \\
management & & Q3 & 0.505 \\
& & Q4 & 0.492 \\
& & Q5 & 0.616 \\
& Q6 & 0.628 \\
\hline Customer focus & 0.815 & Q7 & 0.556 \\
& & Q8 & 0.629 \\
& & Q9 & 0.818 \\
& & Q10 & 0.803 \\
Campus facility & 0.788 & Q13 & 0.593 \\
\hline & & Q14 & 0.365 \\
& & Q15 & 0.72 \\
& & Q16 & 0.753 \\
& & Q17 & 0.635 \\
\hline Course delivery & 0.859 & Q18 & 0.674 \\
& & Q19 & 0.757 \\
& & Q20 & 0.613 \\
& & Q21 & 0.653 \\
& & Q22 & 0.735 \\
& & Q23 & 0.737 \\
& & Q24 & 0.631 \\
\hline Communication & 0.808 & Q26 & 0.586 \\
& & Q27 & 0.836 \\
& & Q28 & 0.725 \\
& Q29 & 0.597 \\
& & Q31 & 0.581 \\
& & & \\
\hline
\end{tabular}


TABLE 3: Second of two results of reliability tests and factor analysis.

\begin{tabular}{lccc}
\hline Determinant & $\begin{array}{c}\text { Cronbach } \\
\text { alpha }\end{array}$ & Item & Loading \\
\hline $\begin{array}{l}\text { Education Service Quality } \\
\text { Congenial }\end{array}$ & 0.799 & Q32 & 0.727 \\
Learning & & Q33 & 0.685 \\
environment & & Q34 & 0.654 \\
& & Q35 & 0.695 \\
Continual & 0.86 & Q36 & 0.578 \\
assessment & & Q38 & 0.559 \\
and & & Q39 & 0.711 \\
improvement & & Q40 & 0.787 \\
& & Q41 & 0.792 \\
& & Q42 & 0.667 \\
\hline Customer & 0.866 & Q43 & 0.779 \\
value & & Q44 & 0.825 \\
& & Q45 & 0.838 \\
& & Q46 & 0.756 \\
& & Q47 & 0.553 \\
Customer & 0.884 & Q48 & 0.587 \\
satisfaction & & Q50 & 0.816 \\
& & Q51 & 0.649 \\
& & Q52 & 0.754 \\
& & Q53 & 0.793 \\
& & Q54 & 0.674 \\
\hline
\end{tabular}




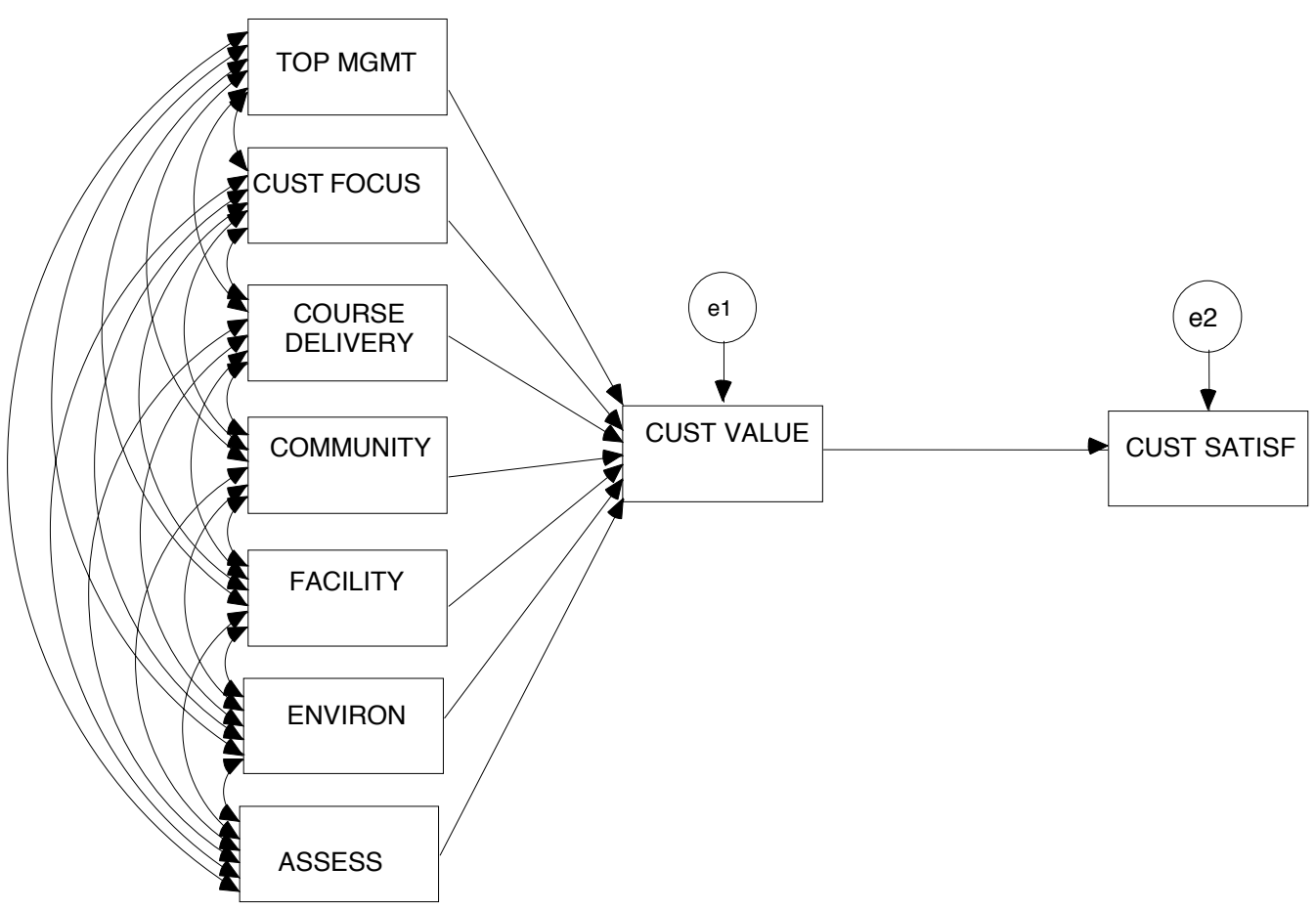

\section{Model 1}

FiguRE 3: First of three models tested for technical education.

factor. All items or dimensions loaded at least 0.30 within the respective factor. Tables 2-3 present detailed results.

Summated scores were calculated for each factor and then used to provide values for each factor. Model I was the initial model adapted from the initial model illustrated in Figure 2. Path analysis simultaneously analyzed the relationships between ESQ factors and Customer Value, and between Customer Value and Customer Satisfaction. Model II was a modification of Model I, allowing for direct effects of ESQ factors to Customer satisfaction. Previously, in Model I, all ESQ factors contribute indirectly to Customer Satisfaction 


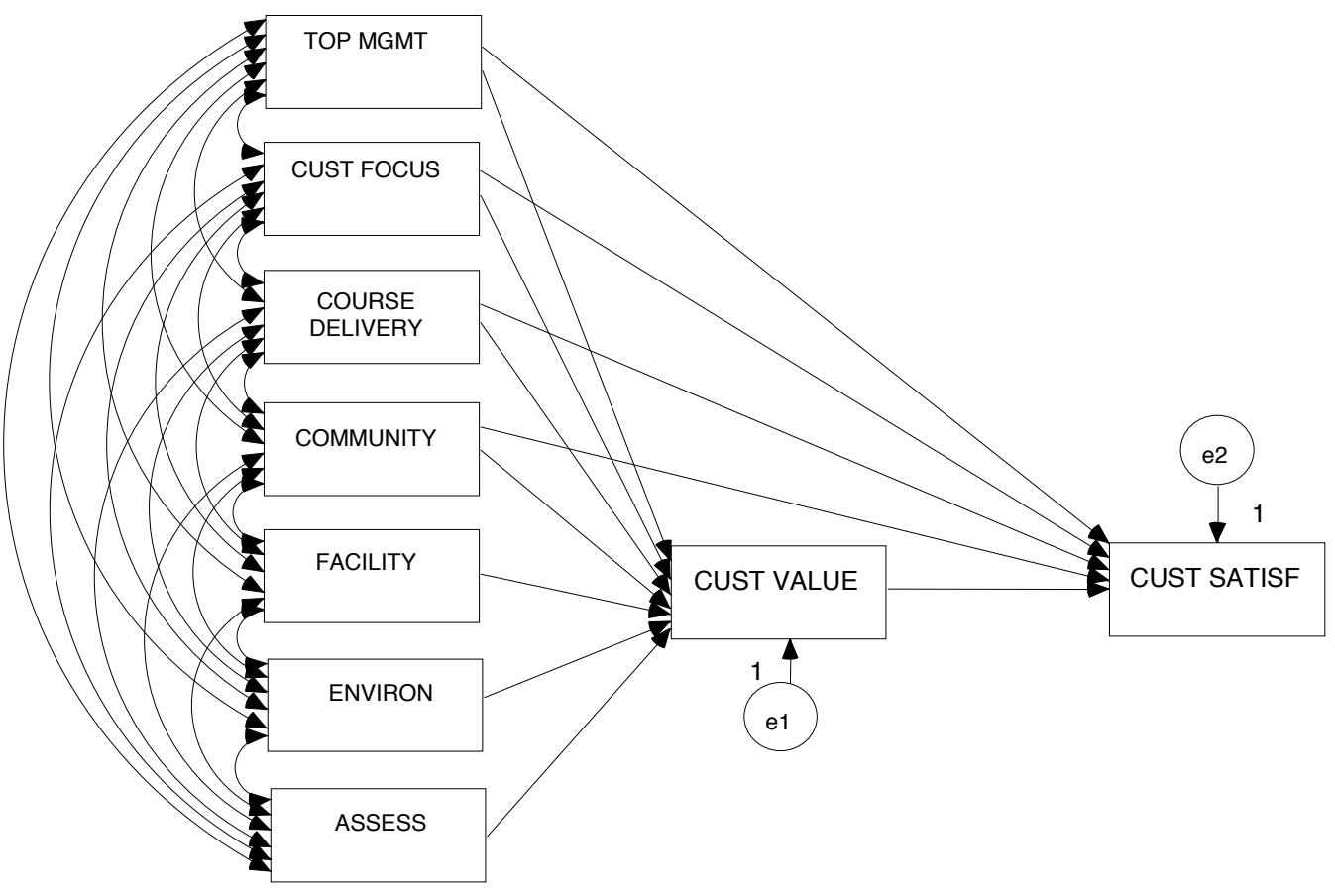

Model II

Figure 4: Second of three models tested for technical education. 


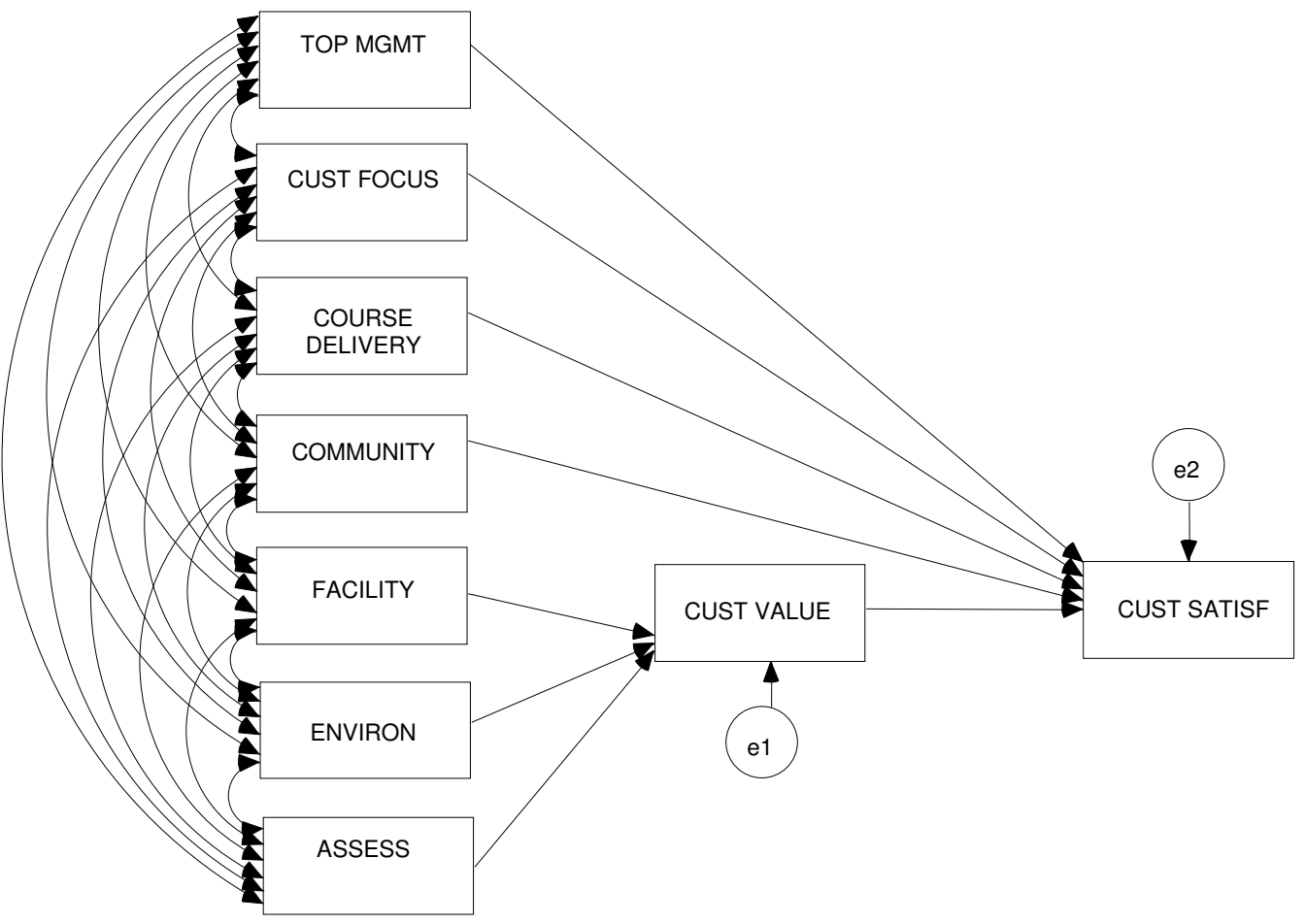

\section{Model III}

FiguRE 5: Last of three models tested for technical education. 
TABLE 4: Results for model fit test

\begin{tabular}{lccc}
\hline Measurement & $\begin{array}{c}\text { Index } \\
\text { Model I }\end{array}$ & $\begin{array}{c}\text { Index } \\
\text { Model II }\end{array}$ & $\begin{array}{c}\text { Index } \\
\text { Model III }\end{array}$ \\
\hline$\chi^{2}$ & 74.812 & 1.959 & 2.707 \\
df & 7 & 3 & 7 \\
$p$-value & 0 & 0.581 & 0.911 \\
TLI & 0.769 & 1.008 & 1.015 \\
NFI & 0.952 & 0.999 & 0.998 \\
GFI & 0.943 & 0.998 & 0.997 \\
RMSEA & 0.203 & $0.000(0.000,0.094)$ & $0.000(0.000,0.031)$ \\
AIC & 150.812 & 85.959 & 78.707 \\
\hline
\end{tabular}

through Customer Value. After removing the non-significant relationships in Model II, Model III was developed. For the final result as for model fitting, the specifications of Model I, Model II and Model III are given in Model Fit measurements for each model. The results are given in Figures 3-5. Table 4 presents the results of the Model Fit tests.

Table 4 indicates that Model I was a bad fit for quality in technical education. The p-value is less than 0.05, the error of RMSEA is greater than 0.05, indicating that the hypothesized model cannot be accepted. Model II is an improvement, but Model III is clearly better, with larger p-value, higher fit index measures (such as GFI, NCFI and TLI), and smaller value and range of RMSEA.

Thus, we choose Model III to explain the relationships among the factors for quality in technical education. Based on Figure 6, the relationships between the studied variables are defined as

Customer value $=0.44$ (Continual assessment and improvement) +0.28 (Learning environment)

+0.081 (Commitment top management) $+e_{1},(1)$ 


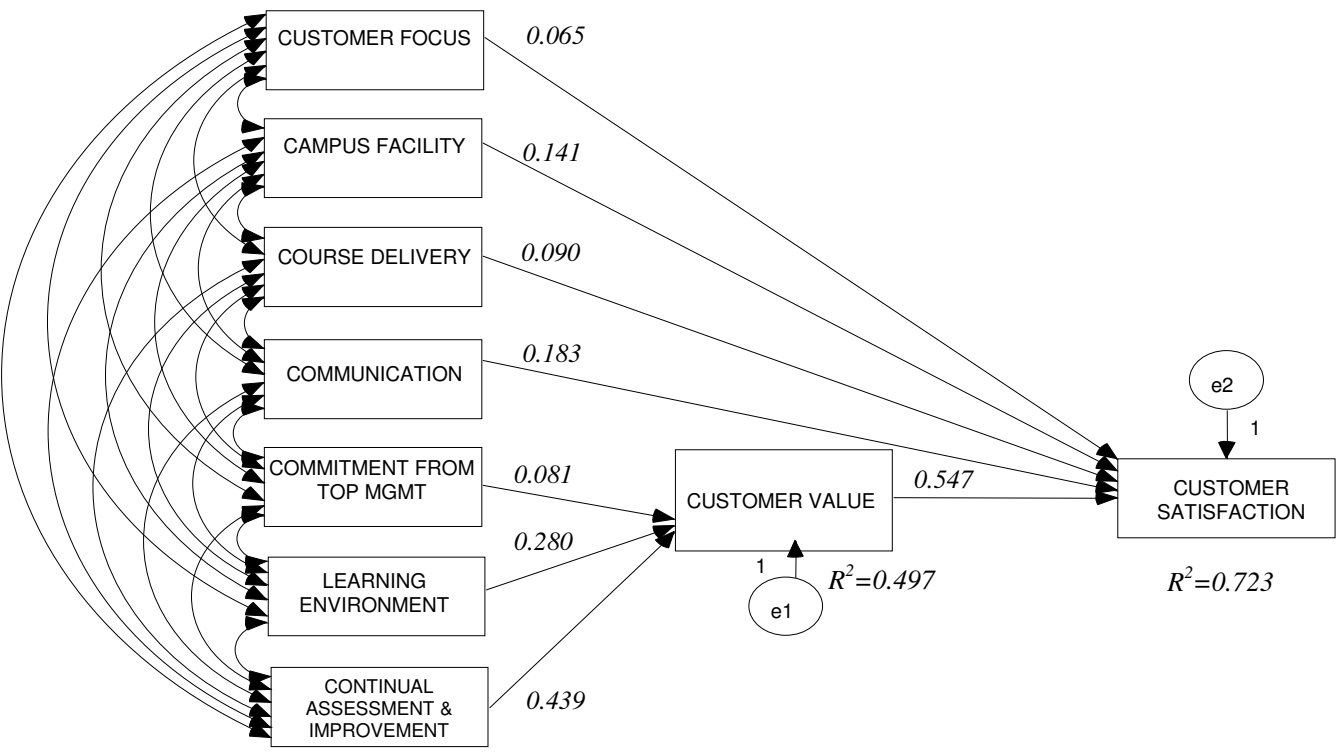

Figure 6: Final model explaining technical education, Model III 


$$
\begin{aligned}
\text { Cust. Satisfaction }= & 0.57 \text { (Customer value) } \\
& +0.18 \text { (Communication) } \\
& +0.14 \text { (Campus facility) } \\
& +0.09 \text { (Course delivery) } \\
& +0.07 \text { (Customer focus })+e_{1} .
\end{aligned}
$$

The analysis results showed that $49.7 \%$ of Customer value was explained by factors of continual assessment and improvement, congenial environment and commitment from top management, while $72.3 \%$ of the variability in Customer satisfaction was explained by customer value, communication, campus facility, course delivery and customer focus. The factor of continual assessment and improvement was the main contributor in Customer value; an increase of a unit in continual assessment and improvement would increase 0.44 units in customer value. For customer satisfaction, the factor of customer value affected the most; the higher the increase in customer value, the more satisfied were the customers.

\section{Discussion and conclusion}

Using the input from technical education students, this study developed a model explaining quality in technical education. The study found that there were three direct effects of TQM determinants on students' value, namely the commitment from top management, learning environment, and continual assessment and improvement. The technical students perceived that the factors of customer focus, course delivery, campus facility and communication directly influenced their satisfaction in the technical education services.

Acknowledgements The authors thank the Universiti Kebangsaan Malaysia for supporting this project under the grant UKM-GUP-BTT-07-25-168, UKMOUP-NBT-27-129/2009 and UKM-GUP-NBT-08-30-124. 


\section{References}

[1] Sahney S., Banwet D. K., Karunes S., Conceptualizing total quality management in higher education, The TQM Magazine 16 (2004) 145-159. http://dx.doi.org/10.1108/09544780410523044 C835, C836, C837, C839

[2] Cheng C. Y., Tam W. M., Multi-models of quality in education, Quality Assurance in Education 5 (1997) 22-31. http://dx.doi.org/10.1108/09684889710156558 C835

[3] Lawrence J. J., McCullogh M. A., A conceptual framework in guaranteeing higher education, Quality Assurance in Education 9 (2001) 139-152. http://dx.doi.org/10.1108/09684880110399103 C835

[4] Hill Y., Lomas L., Mcgregor J., Students;' perceptions of quality in higher education, Quality Assurance in Education 11 (2003) 15-20. http://dx.doi.org/10.1108/09684880310462047 C836

[5] Lo V. H. Y., Sculli D., An application of TQM concepts in education, Training for Quality 4 (1996) 16-22. http://dx.doi.org/10.1108/09684879610125707 C836

[6] Kanji G. K., Tambi A. M. B. A., Wallace W., A comparative study of quality practices in higher education institutions in U.S. and Malaysia, Total Quality Management 10 (1999) 357-371.

http://www. ingentaconnect.com/content/routledg/ctqm/1999/ 00000010/00000003/art00004 C836

[7] Kanji G. K., Tambi A. M. B. A., Total quality management in U.K. higher education institutions, Total Quality Management 10 (1999) 129-153. http://www. ingentaconnect. com/content/routledg/ ctqm/1999/00000010/00000001/art00011 C836

[8] Sakhtivel P. B., Raju R., An instrument for measuring engineering education quality from students' perspective, Quality Management 
Journal 13 (2006) 24-34.

http://asq.org/qic/display-item/index.html?item=20643 C836, C838

[9] Sakhtivel P. B., Rajendran, G., Raju R., TQM implementation and students' satisfaction of academic performance, The TQM Magazine $\mathbf{1 7}$ (2005) 573-589. http://dx.doi.org/10.1108/09544780510627660 C837, C839, C840

\section{Author addresses}

1. N. N. Wan, Malaysian Institute of Chemical and Bioengineering Technology, Kuala Lumpur University, MALAYSIA.

2. N. R. M. Suradi, School of Mathematical Sciences, Faculty of Science and Technology, Universiti Kebangsaan Malaysia, Malaysia.

3. Z. Mustafa, School of Mathematical Sciences, Faculty of Science and Technology, Universiti Kebangsaan Malaysia, Correspondence: Tel: 603-89213597, Fax: 603-89254519, MaLAYSIA. mailto:zbhm@ukm. my

4. W. R. Ismail, School of Mathematical Sciences, Faculty of Science and Technology, Universiti Kebangsaan Malaysia, Malaysia.

5. Z. M. Ali, School of Mathematical Sciences, Faculty of Science and Technology, Universiti Kebangsaan Malaysia, MaLAYsia.

6. F. A. A. Shahabuddin, School of Mathematical Sciences, Faculty of Science and Technology, Universiti Kebangsaan Malaysia, Malaysia. 